\title{
A 12-month prospective study of intra-abdominal hypertension and abdominal compartment syndrome incidence and outcomes at a tertiary hospital in Nigeria
}

\author{
Omobolaji O. Ayandipo', Oludolapo O. Afuwape', Modupe A. Kuti², Tinuola A. Adigun³, Olusola K. Idowu \\ 1. Department of Surgery, College of Medicine, Univeristy of Ibadan, Ibadan, Nigeria \\ 2. Department of Chemical Pathology, College of Medicine, Univeristy of Ibadan, Ibadan, Nigeria \\ 3. Department of Anaesthesia, College of Medicine, Univeristy of Ibadan, Ibadan, Nigeria \\ Correspondence: Dr Oludolapo O. Afuwape (dolafpe@yahoo.co.uk)
}

(c) 2018 0.0. Ayandipo et al. This open access article is licensed under a Creative Commons Attribution 4.0 International License (http://creativecommons.org/licenses/by/4.0/), which permits unrestricted use, distribution, and reproduction in any medium, provided you give appropriate credit to the original author(s) and the source, provide link to the Creative Commons license, and indicate if changes were made.

\begin{abstract}
Background

Peritoneal sepsis is a life-threatening emergency, more so in the low- and middle-income countries (LMICs) where immediate hospital presentation for much needed urgent surgical care is the exception rather than the norm. Continued research into the multifactorial aetiopathogenesis responsible for the high level of morbidity and mortality is necessary. We aimed to determine the incidence of intra-abdominal hypertension (IAH) and abdominal compartment syndrome (ACS) in patients presenting with generalized peritonitis in a tertiary hospital in Nigeria.
\end{abstract}

\section{Methods}

We conducted a prospective study involving recruitment of consenting patients managed for generalized peritonitis over 12 months.

\section{Results}

Fifty-seven consenting and appropriate patients were recruited over the course of the study and managed as per study protocol. The duration of symptoms ranged between 11 hours and 7 days. All patients had varying degrees of IAH and ACS at presentation with generalized peritonitis. A laparotomy with definitive surgery was done in 51 patients (89\%), with 6 patients (11\%) having only a bedside peritoneal drain inserted for decompression.

Significant improvement of the respiratory rate $(P<0.001)$, oxygen saturation $(P=0.041)$, and urinary output $(P=0.021)$ only occurred after decompression by laparotomy or tube drainage. The consecutive mean \pm standard deviation (SD) intra-abdominal pressures measured, respectively, at presentation, immediately postsurgery, then postoperatively at $6 \mathrm{~h}, 24 \mathrm{~h}$, and $72 \mathrm{~h}$ reflected significant improvement at each point (respectively in $\mathrm{CmH}_{2} \mathrm{O}: 11.4 \pm 6.03,6.58 \pm 5.58,5.78 \pm 3.29,4.73 \pm 2.86,6.72 \pm 5.18 ; P<0.001$ ).

\section{Conclusions}

IAH and ACS are not uncommon in our setting, and ACS at presentation is a significant predictor of mortality in patients with peritoneal sepsis. Surgical decompression invariably leads to an improvement in all clinical variables investigated.

Keywords: intra-abdominal hypertension, abdominal compartment syndrome, peritonitis, laparotomy, percutaneous catheter decompression, Nigeria

\section{Introduction}

The morbidity associated with secondary peritonitis often leads to prolonged hospital admission, sepsis, and multiorgan failure; death occurs in $20 \%$ to $60 \%$ of cases. ${ }^{1-5}$ Intra-abdominal hypertension (IAH) is a sustained or repeated pathologic elevation of intra-abdominal pressure (IAP) greater than $12 \mathrm{mmHg}$. Abdominal compartment syndrome
(ACS), so named by Kron et al. ${ }^{6}$ is sustained IAP greater than $20 \mathrm{mmHg}$, with or without an abdominal perfusion pressure (APP) less than $60 \mathrm{mmHg}$, that is associated with new organ dysfunction or failure. ${ }^{78}$ The effect of IAH and ACS on cardiovascular, renal, pulmonary, splanchnic, abdominal wall, and nervous tissues have been elucidated over the last century and a half. ${ }^{9-14}$ IAH and ACS refer to multisystem 


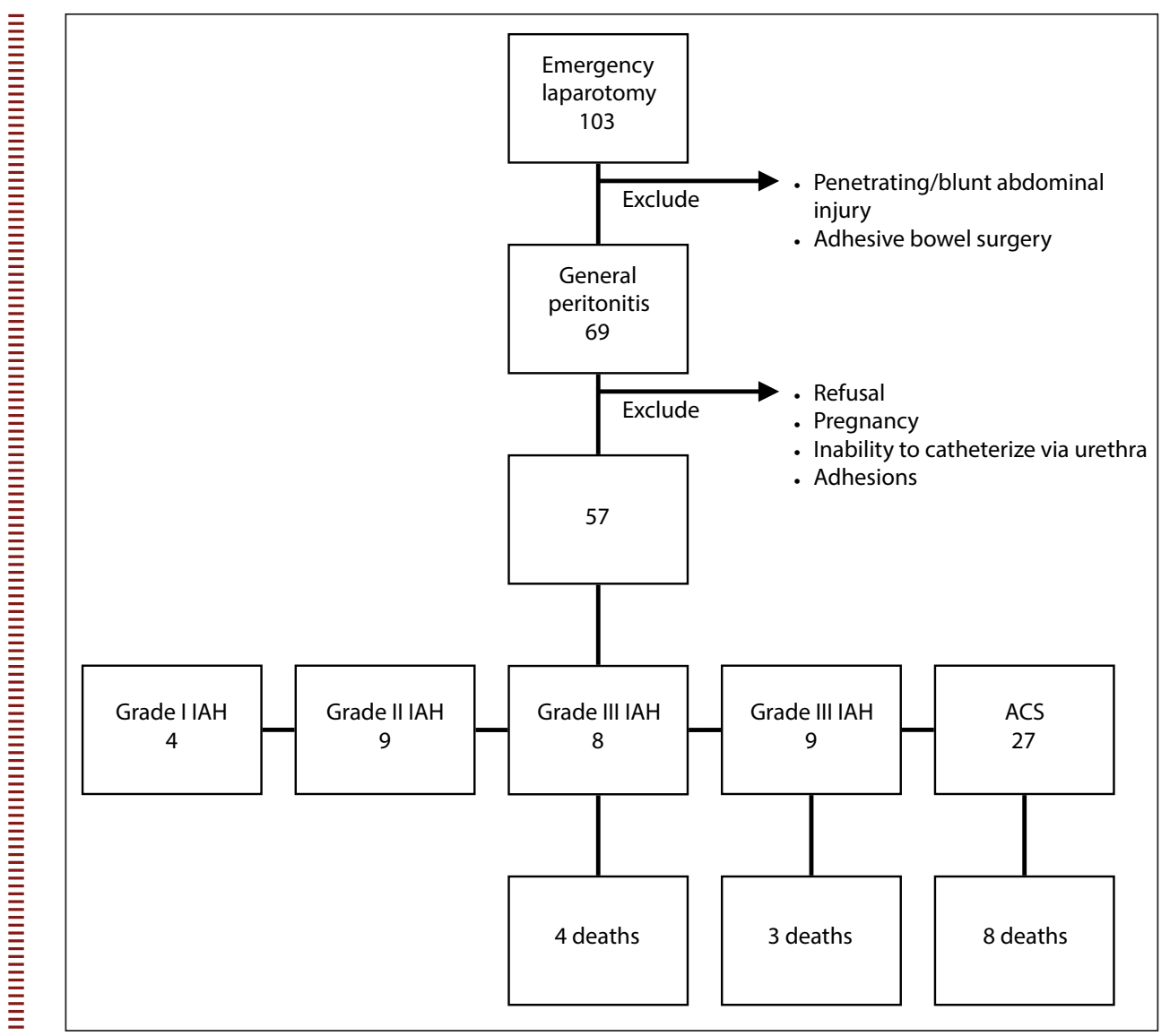

Figure 1. Study recruitment and findings summary

$\mathrm{IAH}=$ intra-abdominal hypertension

$\mathrm{ACS}=$ abdominal compartment syndrome

pathological entities resulting from IAP elevation regardless of aetiology. ${ }^{15}$ The clinical spectrum should not be allowed to run its course, and while many of the potential early management options for IAH are medical interventions (haemodialysis, neuromuscular blocking agents, diuretics, prokinetic agents) that vary depending on aetiology, early surgical decompressive laparotomy is the gold standard for ACS. ${ }^{16-21}$ The transient, though physiologically mediated, IAP elevations that occur during cough, heavy object lifting, and Valsalva manoeuvre cannot be sustained or tolerated for long periods. $^{22,23}$

Peritoneal sepsis from a gastrointestinal pathology serves as the first pathologic insult, while the resulting acute increase in IAP greater than $15 \mathrm{mmHg}$ causes an impairment of intestinal oxygenation and, at IAPs greater than 40 $\mathrm{mmHg}$, mesenteric blood flow actually reduces by $60 \%$ to $70 \%,{ }^{24}$ resulting in impaired gut mucosal barrier function and leading to bacterial endotoxin translocation and sepsis as an escalation of the first insult. ${ }^{25}$ The multisystemic effect of the worsening IAP on the adjoining organ systems (thoracic, kidney, venous) serves as the second pathologic insult in patients with secondary peritonitis. ${ }^{6}$ The occurrence of IAH and ACS has been thoroughly investigated in mostly homogeneous patients groups-mainly trauma, vascular, and intensive care unit (ICU) patients ${ }^{26,27}$ with less attention given to secondary peritonitis either at presentation or postoperatively. More important is the absence of any review in
sub-Saharan Africa on this self-perpetuating, multisystem, and multifactorial syndrome. The clinical applications of relevant diagnostic and therapeutic advancements are well documented in relation to the developed world, while research and publications from sub-Saharan Africa are lacking. ${ }^{26,27}$ This study aimed to determine: (1) the incidence of IAH and ACS, (2) if IAH/ACS is an independent predictor of morbidity and mortality, and (3) the outcomes of management of secondary peritonitis patients with IAH or ACS.

\section{Methods}

We conducted a prospective study in the Division of Gastrointestinal Surgery, Department of Surgery, University College Hospital (UCH), Ibadan, Nigeria. Patients with a clinical diagnosis of generalized peritonitis secondary to a gastrointestinal organ pathology were enrolled and followed over a 12-month period from April 2015 to March 2016. Consenting patients over the age of 18 undergoing emergency laparotomy for peritoneal sepsis were eligible. We excluded patients who refused to provide consent, and those who were obese, pregnant, diagnosed with adhesive intestinal obstruction, or for whom urethral catheterization failed. The protocol involved recruitment at presentation. Ethical approval was obtained from the state institutional review board under the Ministry of Health (MOH).

Sociodemographic characteristics, along with vital signs; clinical diagnosis; biochemical, haematological and radiological workup results; and intraoperative and postoperative details were recorded. The surgical intervention, presence or absence of high dependency unit (HDU) or ICU care, and outcomes (morbidity and mortality) were all recorded. We also recorded IAPs at presentation, immediately postoperatively $(0 \mathrm{~h})$, and then at $6 \mathrm{~h}, 24 \mathrm{~h}$, and $72 \mathrm{~h}$ postsurgery.

\section{Intra-abdominal pressure measurement}

With the patient in the supine position, IAP was indirectly measured, as described by Kron et al., ${ }^{6}$ by passing a $16 \mathrm{Fr}$ Foley catheter into the urinary bladder; further to emptying the bladder, we instilled $50 \mathrm{~mL}$ of sterile normal saline and clamped the collecting bag, after which a saline manometer was connected. The pubic symphysis served as the ref- 
Table 1. Patient demographic and clinical characteristics

\begin{tabular}{|c|c|}
\hline Characterstic & n (\%) \\
\hline \multicolumn{2}{|l|}{ Age (years) } \\
\hline $18-40$ & $30(53)$ \\
\hline $41-65$ & $17(30)$ \\
\hline$\geq 66$ & $10(18)$ \\
\hline \multicolumn{2}{|l|}{ Gender } \\
\hline Male & $38(67)$ \\
\hline Female & $19(33)$ \\
\hline \multicolumn{2}{|l|}{ Clinical diagnosis (intra-abdominal site of origin) } \\
\hline Gastroduodenal & $11(19)$ \\
\hline Small bowel & $15(26)$ \\
\hline Appendix & $18(32)$ \\
\hline Colon & $9(16)$ \\
\hline Biliary & $4(7)$ \\
\hline \multicolumn{2}{|l|}{ Comorbidities } \\
\hline Hypertension & $14(25)$ \\
\hline Diabetes mellitus & $11(19)$ \\
\hline Asthma & $2(4)$ \\
\hline \multicolumn{2}{|l|}{ Anaesthesia } \\
\hline General anaesthesia & $44(77)$ \\
\hline Local anaesthesia & $13(23)$ \\
\hline Subarachnoid block & 0 \\
\hline \multicolumn{2}{|l|}{ Surgeon } \\
\hline Senior registrar & $22(39)$ \\
\hline Consultant & $35(61)$ \\
\hline \multicolumn{2}{|l|}{ Surgical Intervention } \\
\hline Laparotomy and definitive surgery & $51(89)$ \\
\hline Peritoneal (tube) decompression only & $6(11)$ \\
\hline \multicolumn{2}{|l|}{ Postoperative care } \\
\hline High-dependency unit & $28(49)$ \\
\hline Intensive care unit & $16(28)$ \\
\hline Ward & $13(23)$ \\
\hline \multicolumn{2}{|l|}{ Outcome } \\
\hline Dead & $15(26)$ \\
\hline Alive & $42(74)$ \\
\hline \multicolumn{2}{|l|}{ Postoperative morbidity } \\
\hline Anastomotic leak/enterocutaneous fistula & $3(5)$ \\
\hline Acute respiratory distress syndrome & $6(11)$ \\
\hline Burst abdomen & $6(11)$ \\
\hline Wound infection & $41(72)$ \\
\hline Abscess - organ space & $6(11)$ \\
\hline
\end{tabular}

erence point, while pressure was measured initially in $\mathrm{cmH}_{2} \mathrm{O}$ at the end of expiration before conversion to $\mathrm{mmHg}$. We used the World Society of the Abdominal Compartment Syndrome (WSACS) grading system for $\mathrm{IAH},{ }^{8}$ as follows: Grade I: $12-15 \mathrm{mmHg}$, Grade II: 16-20 mmHg, Grade III: 21-25 mmHg, and Grade IV: $\geq 25 \mathrm{mmHg}$. ACS was deemed to have occurred when IAH and 1 newly diagnosed organ system dysfunction occurred. Statistical analysis was performed using SPSS version 21 (IBM Inc., Armonk, NY, USA). Categorical and continuous variables are presented as numbers and percentages and mean \pm standard deviation (SD), respectively. Significance testing for variables obtained before and after operative intervention was done using the paired sample t-test, and trends in IAP were compared using analysis of variance (ANOVA). Statistical significance was set at $P \leq 0.05$.

\section{Results}

Over the 1-year study period, 103 emergency laparotomies were performed in the gastrointestinal surgery division at UCH, Ibadan. Of these 69 (67\%) were for peritoneal sepsis and $12(12 \%)$ were excluded due to reasons of refusal, pregnancy, adhesive intestinal obstruction, and inability to catheterize via the urethra. A total of 57 patients (55\%) were consecutively recruited. The mean age \pm SD was $48 \pm 12$ years. Figure 1 shows the findings of the study, and Table 1 shows the sociodemographic and clinical characteristics of the patients. Comorbidities noted were hypertension, 


\begin{tabular}{l|c|c}
\hline \multicolumn{2}{l}{$\begin{array}{l}\text { Table 2. Incidence and outcomes of intra-abdmonial } \\
\text { hypertension (IAH) and abdominal compartment syn- } \\
\text { drome (ACS) among patients with peritonitis }\end{array}$} \\
\hline Severity & $\mathbf{n}(\%)$ & $\begin{array}{c}\text { Deaths } \\
\mathbf{n}\end{array}$ \\
\hline \hline Grade 1 IAH & $4(7)$ & 0 \\
Grade 2 IAH & $9(16)$ & 0 \\
Grade 3 IAH & $8(14)$ & 4 \\
Grade 4 IAH & $9(16)$ & 3 \\
ACS & $27(47)$ & 8 \\
\hline
\end{tabular}

diabetes mellitus, and asthma in, respectively, $14 \pm 25 \%$, $11 \pm 19 \%$, and $2 \pm 4 \%$ of patients. All patients had signs of peritonitis (guarding, rebound tenderness, and board-like rigidity, along with at least 2 systemic inflammatory response syndrome (SIRS) criteria. The duration of symptoms ranged between 11 hours and 7 days. Preoperative resuscitation before surgical intervention was administered for between 1 and 8 days. Fifty-one patients (89\%) underwent laparotomy with definitive surgery, and 6 patients $(11 \%)$ had a bed-side peritoneal drain inserted for decompression instead of laparotomy. A mean of $1400 \mathrm{~mL}$ (range $900-5300 \mathrm{~mL}$ ) of pus was drained from the patients. The diagnoses and interventions are listed in Table 1 . The majority of patients (75\%) were nursed in the HDU or ICU because of the need for vasoactive support or elective ventilation.

All patients recruited had at least Grade I IAH at presentation. Table 2 highlights the incidence and outcomes of IAH and ACS in this patient group. Postoperative morbidity occurred in 46 patients $(81 \%)$ (Table 1 ). Nine patients (16\%) had to be re-explored on account of burst abdomen and organ space infection (abscess). Blood pressures, pulse rates, pulse volumes, and body temperatures improved following resuscitation, while the respiratory rates $(P<0.001)$, oxygen saturations $(P<0.041)$, and urine outputs $(P<0.021)$ improved significantly only after surgical decompression by laparotomy or percutaneous tube drainage. The mean duration of hospital stay was 11 days (range 8-25 days). The mean \pm SD IAPs measured, respectively, at presentation, immediately postsurgery, then postoperatively at $6 \mathrm{~h}, 24 \mathrm{~h}$, and $72 \mathrm{~h}$ reflected significant improvement with each consecutive measurement: $11.4 \pm 6.03 \mathrm{cmH}_{2} \mathrm{O}, 6.58 \pm 5.58 \mathrm{cmH}_{2} \mathrm{O}$, $5.78 \pm 3.29 \mathrm{cmH}_{2} \mathrm{O}, 4.73 \pm 2.86 \mathrm{cmH}_{2} \mathrm{O}, 6.72 \pm 5.18 \mathrm{cmH}_{2} \mathrm{O}$; $P<0.001)$.

\section{Discussion}

Our study was on a homogeneous cohort with IAH or ACS occurring secondary to pathology in the abdominopelvic region and requiring surgical or interventional radiological management. ${ }^{28}$ Notably, most studies on IAH and ACS analyse either trauma or ICU patients, ${ }^{29}$ and the presence of IAH is associated with an 11-fold rise in mortality. ${ }^{30}$

The male-to-female ratio in our study closely mirrored studies from other parts of the world, ${ }^{29,31,32}$ while the mean age of $48 \pm 12$ years was similar to the earlier report by
Cheatham et al. ${ }^{33}$ but distinctly higher than values reported by others. ${ }^{29,31,32}$ Peritonitis as a consequence of (blunt) trauma represented only $9 \%$ of patients recruited, which contradicted the $17-68 \%$ reported in other reviews. ${ }^{29,33}$ The mechanism of peritonitis in these cases progressed from bowel devascularization, to indolent ischaemia, and subsequent necrosis or perforation; this differs from the classical characterization of haematoperitoneum and shock seen in the study by Meldrum et al. ${ }^{32}$

The prevalence of IAH in our sample was $100 \%$ at admission, which is higher than the value reported by Khan et al., ${ }^{29}$ while the $47 \%$ incidence of ACS is also higher than other reports by various authors. ${ }^{8}$ Subtle differences in the population of patients used, including trauma, ICU uptake, peritoneal sepsis presence, and cutoff values have all been implicated in the wide range of values reported. ${ }^{8}$ It is, however, clear when using the consensus definition of ACS that incidence will be higher in the context of peritoneal sepsis because organ dysfunction may not be solely attributed to an increasing peritoneal pressure but also from the sepsis to multiple organ dysfunction syndrome (MODS) pathway. The organ dysfunction can be explained by either sepsis or MODS potentiating IAH or vice versa to cause the progression to ACS. The increase in IAP seen in peritonitis is a result of an accumulation of gas, pus, faeces, or peritoneal and bowel oedema. The mean \pm SD IAP at presentation of $11.4 \pm 6.03$ is lower than quoted values from other studies, while the postsurgical decompression value closely matches other reported values. $^{29,30,32}$ The lower preintervention IAH values seen in our cohort support our argument that the organ dysfunction noted in our patient group (which necessitated classifying those patients as ACS) may not be mainly due to the peritoneal pressure increase but rather to sepsis. Of note, however, is the large volumes of pus, faeces, or air drained from the peritoneal cavity at decompressive laparotomy.

The resolution of oliguria, uraemia, and raised creatinine after resuscitation and decompression suggest that baseline data can be assumed to have been normal before onset of illness. Abdominal wall closure was done primarily. Despite the seeming lack of abdominal wall tension, as evidenced by the tight-looking sutures, there was no IAH observed in the immediate postoperative period. This may be attributed to the perioperative manoeuvres of bowel decompression using the nasogastric tube, to urethral catheterization, or to the use of the Savage decompressor, along with the previously mentioned medical options and nonreversal of neuromuscular function when postoperative elective ventilation was required. Reported cases of immediate postoperative IAH are more common in trauma, where damage control and pressure packing are employed with or without the use of (modified) Bogota bags. Although no IAH was noted postsurgery, some patients developed organ system failure; we believe that this is a representative group of patients in whom the aetiopathogenesis of organ dysfunction is more sepsis-based than IAH-based. They formed a high proportion of patients who died before reaching the $72 \mathrm{~h}$ mark after surgical intervention.

Our analysis showed that decompressive laparotomy in our patients resulted in improved renal, respiratory, cardio- 
vascular indices. The respiratory system-represented clinically by the respiratory rate, oxygen saturation, and the need for ventilator support (or lack thereof) - showed statistically significant improvement. The renal and cardiovascular systems showed improvement, though this was not statistically significant. This finding was contrary to the findings reported by Khan et al. ${ }^{29}$ and Ma et al. ${ }^{34}$ who demonstrated a statistically significant improvement in renal function. Our mean pre- and post-decompression urine outputs were similar to those reported by Sugrue et al. ${ }^{30}$

Although found predominantly in a mixed ICU patient population, the most common risk factors found in a systemic review and meta-analysis included large-volume crystalloid resuscitation, patient respiratory state, sepsis, and the presence of shock or hypotension (systolic blood pressure
$<86 \mathrm{mmHg}){ }^{26}$ This was the norm rather than the exception in our cohort, as they were all present to varying degrees in our patients. Surgical intervention within 75 minutes of presentation has also been reported as a key predictor ${ }^{35}$; but due to the resuscitation requirement in established cases of peritoneal sepsis, our mean time from presentation to surgery was 3 days (range 1-8). The extended duration of resuscitation was due to the need to optimize the patients that presented with septic shock, acute kidney injury, or other states of severe decompensation.

\section{Competing interests}

All authors declare that they have no competing interests related to this work.

\section{References}

1. Christou NV, Barie PS, Dellinger EP, Waymack JP, Stone HH. Surgical Infection Society intra-abdominal infection study: prospective evaluation of management techniques and outcome. Arch Surg. 1993 Feb;128(2):193-8; discussion 198-9. doi: 10.1001/archsurg.1993.01420140070011.

2. Koperna T, Schulz F. Prognosis and treatment of peritonitis. Do we need new scoring systems? Arch Surg. 1996 Feb;131(2):180-6. doi: 10.1001/ archsurg.1996.01430140070019.

3. Wittmann DH, Schein $M$, Condon RE Management of secondary peritonitis Ann Surg. 1996 Jul;224(1):10-8

4. Lamme B, Boermeester MA, Belt EJ, van Till JW, Gouma DJ, Obertop H. Mortality and morbidity of planned relaparotomy versus relaparotomy on demand for secondary peritonitis. Br J Surg. 2004 Aug;91(8):1046-54. doi: 10.1002/bjs.4517.

5. Rakić M, Popović D, Rakić M, Druzijanić N, Lojpur M, Hall BA, et al. Comparison of on-demand vs planned relaparotomy for treatment of severe intra-abdominal infections. Croat Med J. 2005 Dec;46(6):957-63.

6. Kron IL, Harman PK, Nolan SP. The measurement of intra-abdominal pressure as a criterion for abdominal reexploration. Ann Surg. 1984 Jan;199(1):2830.

7. Malbrain ML, De Laet I, Cheatham M Consensus conference definitions and recommendations on intra-abdominal hypertension $(\mathrm{IAH})$ and the abdominal compartment syndrome (ACS) - the long road to the final publications, how did we get there? Acta Clin Belg. 2007;62 Suppl 1:44-59. doi: 10.1179/acb.2007.62 s1.007.

8. Cheatham ML, Malbrain ML, Kirkpatrick A, Sugrue M, Parr M, De Waele J, et al. Results from the International Conference of Experts on Intra-abdominal Hypertension and Abdominal Compartment Syndrome. II. Recommendations. Intensive Care Med. 2007 Jun;33(6):951-62. doi: 10.1007/ s00134-007-0592-4. Epub 2007 Mar 22.
9. Bradley SE, Bradley GP. The effect of increased intra-abdominal pressure on renal function in man. J Clin Invest. 1947 Sep:26(5):1010-22. doi: 10.1172/ JCl101867.

10. Wendt E. Uber den einfluss des intraabdominalen druckes auf die absonderungsgeschwindigkeit des harnes. Arch Physiol Heilkunde 1876:57:525-7.

11. Schein M. Abdominal compartment syndrome: historical background. In: Ivatury $R$, Cheatham M, Malbrain $M$, Sugrue $M$, editors. Abdominal compartment syndrome. Georgetown (TX): Landes Biosciences; 2006. p. 1-7.

12. Van Hee R. Historical highlights in concept and treatment of abdominal compartment syndrome. Acta Clin Belg. 2007:62 Suppl 1:9-15. doi: 10.1179/ acb.2007.62.s1.003.

13. Cheatham ML. Intra-abdominal hypertension and abdominal compartment syndrome. New Horizons. 1999;7:96-115.

14. Coombs HC. The mechanism of the regulation of intra-abdominal pressure. Am J Physiol. 1922;61:159-70.

15. Saggi BH, Sugerman HJ, Ivatury RR, Bloomfield GL. Abdominal compartment syndrome. J Trauma. 1998 Sep;45(3):597609.

16. Morris JA Jr, Eddy VA, Blinman TA Rutherford EJ, Sharp KW. The staged celiotomy for trauma. Issues in unpacking and reconstruction. Ann Surg. 1993; 217(5):576

17. De Laet I, Hoste E, Verholen E, De Waele JJ. The effect of neuromuscular blockers in patients with intra-abdominal hypertension. Intensive Care Med. 2007 Oct;33(10):1811-4. doi: 10.1007/s00134007-0758-0. Epub 2007 Jun 27
18. Hakobyan RV, Mkhoyan GG. Epidural analgesia decreases intraabdominal pressure in postoperative patients with primary intra-abdominal hypertension. Acta Clin Belg. 2008 Mar-Apr;63(2):86-92. doi: 10.1179/acb.2008.63.2.005.

19. Gotlieb WH, Feldman B, FeldmanMoran O, Zmira N, Kreizer D, Segal Y, et al. Intraperitoneal pressures and clinical parameters of total paracentesis for palliation of symptomatic ascites in ovarian cancer. Gynecol Oncol. 1998 Dec;71(3):381-5. doi: 10.1006/ gyno.1998.5215.

20. Mohmand $H$, Goldfarb S. Renal dysfunction associated with intraabdominal hypertension and the abdominal compartment syndrome. J Am Soc Nephrol. 2011 Apr;22(4):615-21. doi: 10.1681/ASN.2010121222. Epub 2011 Feb 10.

21. Cheatham ML. Abdominal compartment syndrome: pathophysiology and definitions. Scand J Trauma Resusc Emerg Med. 2009 Mar 2;17:10. doi: 10.1186/17577241-17-10.

22. Shafik A, El-Sharkawy A, Sharaf WM. Direct measurement of intra-abdominal pressure in various conditions. Eur J Surg. 1997 Dec;163(12):883-7.

23. de Cleva R, Silva FP, Zilberstein $B$ Machado DJ. Acute renal failure due to abdominal compartment syndrome: report on four cases and literature review. Rev Hosp Clin Fac Med Sao Paulo. 2001 Jul-Aug;56(4):123-30. doi: 10.1590/S004187812001000400006

24. Bongard F, Pianim N, Dubecz S, Klein SR. Adverse consequences of increased intra-abdominal pressure on bowel tissue oxygen. J Trauma. 1995 Sep;39(3):519-24; discussion 524-5.

25. Diebel LN, Dulchavsky SA, Brown WJ. Splanchnic ischemia and bacterial translocation in the abdominal compartment syndrome. J Trauma. 1997 Nov:43(5):852-5. 
26. Holodinsky JK, Roberts DJ, Ball CG, Blaser AR, Starkopf J, Zygun DA, et al. Risk factors for intra-abdominal hypertension and abdominal compartment syndrome among adult intensive care unit patients: a systematic review and meta-analysis. Crit Care. 2013 Oct 21;17(5):R249. doi: 10.1186/cc13075.

27. De Waele JJ, Hoste EA, Malbrain ML. Decompressive laparotomy for abdominal compartment syndrome--a critical analysis. Crit Care. 2006;10(2):R51. doi: 10.1186/cc4870.

28. Kirkpatrick AW, Roberts DJ, De Waele J, Jaeschke R, Malbrain ML, De Keulenaer B, et al. Intra-abdominal hypertension and the abdominal compartment syndrome: updated consensus definitions and clinical practice guidelines from the World Society of the Abdominal Compartment Syndrome. Intensive Care Med. 2013 Jul;39(7):1190-206. doi: 10.1007/s00134013-2906-z. Epub 2013 May 15.

29. Khan S, Verma AK, Ahmad SM, Ahmad R. Analyzing intra-abdominal pressures and outcomes in patients undergoing emergency laparotomy. J Emerg Trauma Shock. 2010 Oct;3(4):318-25. doi: 10.4103/0974-2700.70747.
30. Sugrue M, Buist MD, Hourihan F, Deane S, Bauman A, Hillman K. Prospective study of intra-abdominal hypertension and renal function after laparotomy. $\mathrm{Br} J$ Surg. 1995 Feb;82(2):235-8. doi: 10.1002/ bjs. 1800820234 .

31. Hong JJ, Cohn SM, Perez JM, Dolich MO, Brown M, McKenney MG. Prospective study of the incidence and outcome of intra-abdominal hypertension and the abdominal compartment syndrome. $\mathrm{Br} J$ Surg. 2002 May;89(5):591-6. doi: 10.1046/j.1365-2168.2002.02072.x.

32. Meldrum DR, Moore FA, Moore EE, Franciose RJ, Sauaia A, Burch JM. Prospective characterization and selective management of the abdominal compartment syndrome. Am J Surg. 1997 Dec;174(6):667-72; discussion 672-3. doi: 10.1016/S0002-9610(97)00201-8.

33. Cheatham ML, White MW, Sagraves SG, Johnson JL, Block EF. Abdominal perfusion pressure: a superior parameter in the assessment of intraabdominal hypertension. J Trauma. 2000 Oct;49(4):621-6; discussion 626-7.
34. Ma YM, Qian C, Xie F, Zhou FH, Pan L, Song Q. [Acute renal failure due to abdominal compartment syndrome]. [Article in Chinese]. Zhonghua Yi Xue Za Zhi. 2005 Aug 17:85(31):2218-20. doi: 10.3760/j:is sn:0376-2491.2005.31.015.

35. Balogh Z, McKinley BA, Holcomb JB, Miller CC, Cocanour CS, Kozar RA. Both primary and secondary abdominal compartment syndrome can be predicted early and are harbingers of multiple organ failure. J Trauma. 2003 May;54(5):84859; discussion 859-61. doi: 10.1097/01. TA.0000070166.29649.F3.

36. Madigan MC, Kemp CD, Johnson JC, Cotton BA. Secondary abdominal compartment syndrome after severe extremity injury: are early, aggressive fluid resuscitation strategies to blame? J Trauma. 2008 Feb;64(2):280-5. doi: 10.1097/TA.0b013e3181622bb6. 